\title{
ATRAVESSANDO AS PORTAS DOS PUTEIROS: COMO AS TEORIAS FEMINISTAS CHEGAM NA ZONA?
}

\author{
PASANDO POR LAS PUERTAS DE LOS PROSTÍBULOS: \\ ¿CÓMO ENTRAN EN EL BURDEL LAS TEORÍAS FEMINISTAS? \\ GOING THROUGH THE BROTHELS' DOORS: \\ HOW DO FEMINIST THEORIES GET INTO THE CATHOUSE?
}

\author{
Adriely Clarindo ${ }^{1}$, Jésio Zamboni² e Rafaela Martins ${ }^{3}$ \\ ${ }^{1}$ Universidade Estadual de Campinas, Campinas/SP, Brasil \\ ${ }^{2}$ Universidade Federal do Espírito Santo, Vitória/ES, Brasil
}

${ }^{3}$ Universidade Estadual do Norte Fluminense. Campos dos Goytacazes/RJ, Brasil

\begin{abstract}
RESUMO: Muitos estudos sobre prostituição e prostitutas não apresentam os sentidos e significados atribuídos por elas sobre a própria vida e trabalho. Em vista disso, aliançando-me ao que colegas prostitutas relatavam sobre o assunto e a discussões realizadas junto a parceiros acadêmicos, esta pesquisa é construída através das minhas viagens como puta e pesquisadora a três diferentes zonas, objetivando compreender como as teorias feministas chegam por lá. Narrativas de prostitutas e concepções de algumas teóricas feministas sobre prostituição são entremeadas como forma de compor o debate. Para realizá-lo, entrelaço a proposta de Donna Haraway sobre saberes localizados ao modo de narração oferecido pelo filósofo Walter Benjamin, como forma de contestar narrativas hegemônicas sobre prostituição, assim como afirmar minha conexão parcial com as prostitutas. Por fim, noto que os feminismos quase não chegam às zonas pesquisadas, e quando chegam o fazem através de discursos culpabilizantes.
\end{abstract}

PALAVRAS CHAVE: Prostituição; Feminismos; Gênero.

RESUMEN: Muchos estudios sobre prostitución y prostitutas no presentan los sentidos y significados que atribuyen a su propia vida y trabajo. En vista de esto, uniéndome a lo que las compañeras prostitutas informaron sobre el tema y las discusiones mantenidas con socios académicos, esta investigación se construye a través de mis viajes como puta e investigadora a tres burdeles diferentes, con el objetivo de comprender cómo llegan las teorías feministas. Las narrativas de las prostitutas y las concepciones de algunas teóricas feministas sobre la prostitución se entrelazan como una forma de componer el debate. Para lograrlo, utilizo la propuesta de Donna Haraway sobre el conocimiento localizado al modo de narración que ofrece el filósofo Walter Benjamin, como una forma de cuestionar las narrativas hegemónicas sobre la prostitución, así como afirmar mi conexión parcial con las prostitutas. Finalmente, observo que los feminismos apenas llegan a los burdeles investigados, y cuando lo hacen, lo hacen a través de discursos culpables.

PALABRAS CLAVE: Prostitución; Feminismo; Género.

ABSTRACT: Many studies about prostitution and prostitutes do not present the senses and meanings they attribute to their own life and work. In view of this, joining what fellow prostitutes reported on the subject and discussions held with academic partners, this research is built through my travels as a whore and researcher to three different brothels, aiming to understand how feminist theories get there. Narratives of prostitutes and conceptions of some feminist theorists about prostitution are intertwined as a way of composing the debate. To accomplish it, I interwine Donna Haraway's proposal on localized knowledge to the mode of narration offered by the philosopher Walter Benjamin, as a way of contesting hegemonic narratives about prostitution, as well as affirming my partial connection with prostitutes. Finally, I note that feminisms hardly reach the researched brothels, and when they do, they do so through blaming speeches.

KEYWORDS: Prostitution; Feminisms; Gender. 


\section{Introduzindo os embates entre feminismos e prostituição: mapeando cenários}

As estereotipadas putas: batom escuro, salto alto, roupa curta, olhar vazio e penetrante, um cigarro, um drinque, safada. Assim eram as imagens que povoavam nossa imaginação. Imagens que não surgiram aleatoriamente entre nossos antigos devaneios, essas figuras previamente delineadas retratam o lugar proposto às prostitutas, este que parece ser formidável quando compreendido por meio do olhar vitimizador ou punitivo que entende prostitutas como perdidas, prontas para serem resgatadas, e, quando não, mulheres sem caráter, desavergonhadas.

Estes antigos devaneios universalizantes introduzem este artigo como meio de apontar um cenário que se apresenta diante de leituras realizadas sobre alguns estudos em psicologia sobre prostituição e prostitutas. Tal cenário já fora apontado por Claudia Mayorga e André Geraldo Ribeiro Diniz (2018), quando, ao fazerem uma revisão dos estudos sobre o assunto encontrados na psicologia, relataram que, apesar de se fundamentarem em um quadro teórico e conceitual heterogêneo, muitos trabalhos em psicologia partem de uma análise "externa" das experiências das prostitutas.

Os trabalhos referidos por Mayorga e Diniz (2018) fundamentam-se desde em uma abordagem clínica e do desenvolvimento, ou fenomenológicas, e, em sua maioria, trabalhos em psicologia social. Os apontamentos dos autores foram baseados em estudos como os de Olivier Douville (2007; Lopes, Rabelo, \& Pimenta, 2007; Marchiori, 1983; Molina, 2003), por exemplo.

A relevância de se atentar para o horizonte de pesquisas em psicologia que versam sobre o assunto está em perceber que boa parte delas podem subsidiar posições feministas abolicionistas sobre a prostituição. Diante disso, e observando que as discussões feministas são locais de disputas efervescentes sobre assunto, debateremos os distintos modos como as perspectivas feministas compreendem o trabalho sexual, uma vez que é também através deste cenário que observaremos como elas chegam a zona.

Adriana Piscitelli (2005) aponta os contornos do embate. Ela sugere que, para aquelas que compreendem a sexualidade como um elemento na objetificação de mulheres, a prostituição figura como exercício abusivo do sexo, e a prostituta vítima de violência. Para outras que, opostamente, entendem a sexualidade como lócus potencial de liberação feminina, a prostituta surgiria como símbolo de autonomia sexual e uma ameaça potencial ao controle patriarcal sobre a sexualidade das mulheres.

Emaranhando-se a essas disparidades, há ainda outro polo feminista que compreende o sexo como terreno de disputas, e mesmo reconhecendo a existência de uma ordem sexista não a consideram completamente determinante. Neste caso, a prostituição é lida de maneira mais complexa, pois se tem em vista que em dados momentos, nela pode habitar práticas de resistência e de subversão cultural (Piscitelli, 2005).

Quando pensamos no desenrolar destes embates em terras brasileiras, percebemos que na segunda onda do movimento feminista em meados das décadas de 1970 e 1980, a pornografia e a prostituição não estavam em foco, as inquietações giravam em torno da oposição ao regime militar, nas lutas pela redemocratização e contra a violência masculina. Este quadro se alterou ao longo do tempo, e já na terceira onda do movimento, início da década de 1990, podia-se observar visões negativas e ambivalentes sobre a prostituição. 
Neste momento, as feministas se negavam a ouvir as prostitutas, e entendiam que a prostituição era uma exploração contra a mulher (Piscitelli, 2005, 2012).

Essas percepções negativas se intensificaram a partir dos anos 2000, mas ainda assim foram contrapostas pelas intensificações das aproximações entre acadêmicas(os) e trabalhadoras sexuais, estas últimas exigindo serem vistas como sujeitos de direitos e dotados de agência (Piscitelli, 2005, 2012).

Esta breve contextualização histórica surge como meio de, além de localizar o leitor nos debates sobre o tema, anunciar duas importantes considerações: os cuidados necessários às produções sobre o assunto, que devem observar sobretudo a que eixo teórico estão subsidiando pressupostos, e se suas interlocutoras emergem como sujeitos de pesquisa; e as contraposições que trabalhadoras sexuais e pesquisadores que se alinham às reivindicações delas têm realizado.

Observar estas contraposições culmina na percepção de um movimento de mobilização política que vem sendo realizado por prostitutas há algumas décadas no Brasil, a contar da década de 1980 . Na busca por direitos e na luta contra violência e estigmas direcionados às prostitutas, o movimento insurge no horizonte de disputas e, junto à Gabriela Leite $^{1}$, estronda-se a reivindicação de que prostitutas também podem ser feministas.

Desafiando as prescrições feministas sobre o que se espera de quem se intitula como tal, opondo-se principalmente àquele denominado como feminismo radical e que se posiciona a favor da abolição da prostituição, tendo em vista suas concepções vitimizantes sobre as putas, as prostitutas reclamam seu lugar entre as feministas, e se apropriam do termo feminismo criando o putafeminismo.

Recentemente, Monique Prada (2018) também prostituta e militante do movimento organizado de prostitutas, publicou um livro intitulado Putafeminista. Suas asserções explicitam que putafeminismo é o movimento que surge a partir da ideia que trabalhadoras sexuais podem ser feministas, lutando contra o estigma e buscando direitos sem que, para isso, precisem se envergonhar ou abrir mão do próprio trabalho.

Realizada as exposições sobre como algumas literaturas em psicologia subsidiam posições abolicionistas, assim como os debates entre feminismos e prostituição, anunciamos que este trabalho objetiva compreender como os feminismos chegam nas zonas de prostituição onde pesquisamos. Além disso, ao inspirarmo-nos nas concepções putafeministas e afirmarmos as prostitutas como sujeitos de pesquisa e agentes de conhecimento, optamos por entremear as narrativas de suas experiências ao que algumas teóricas feministas argumentam sobre o trabalho sexual.

Apresentamos, por meio disso, como as trabalhadoras sexuais compreendem seu próprio trabalho e tecemos análises críticas às ponderações feministas. Torna-se ainda imperativo apontar que esta pesquisa foi construída a partir das andanças de uma pesquisadora que também é prostituta, e que, ao ir a zona para trabalhar, discute feminismos com suas colegas putas. Aliada a colegas pesquisadores, a puta pesquisadora também trilha o caminho inverso, e as asserções vistas na zona são levadas ao ambiente acadêmico e discutidos entre eles, culminando nas discussões e análises que estão inscritas neste trabalho. 


\section{Entre conexões parciais e narratividade: apostas metodológicas e zonas pesquisadas}

Esta pesquisa foi inscrita majoritariamente por uma puta pesquisadora, diante disso, imaginamos que certa desconfiança acadêmica não se furtará em cair sobre uma psicóloga, puta e feminista que pesquisa as relações entre prostituição e feminismos. Para pensarmos, requeremos as distintas posições que uma pesquisadora pode ocupar, nos alinhamos às ponderações realizadas por Donna Haraway (1995), sobre uma política de posicionamentos onde as pesquisadoras feministas reconhecem sua perspectiva parcial na produção de conhecimento.

A política de posicionamentos para a autora diz respeito a assunção de um "eu divido" que denota posição de parcialidade e não uma universalidade ou posição de uma identidade inocente com os sujeitos de pesquisa (Haraway, 1995). Em nosso caso, vemos a prostituta que se move entre diferentes posicionamentos, buscando por uma conexão parcial com suas interlocutoras de pesquisa e colegas de trabalho, intentando uma produção de saber que não se pretenda universal e que, portanto, não responda em nome de todas as putas.

Essas posições marcadas e móveis, e que permitem a admissão de uma conexão parcial são, segundo Haraway (1995), aquilo que possibilita a produção de uma objetividade feminista. Esta última não diz respeito a modelos transcendentes de compreensão sobre o mundo, mas sim de saberes localizados. Saberes que podem ser considerados objetivos na medida em que seu caráter é local e parcial. Aqui não há pretensão de neutralidade, transcendência e divisão entre sujeito e objeto, as interlocutoras da pesquisa são também agentes de conhecimentos.

Além disso, neste trabalho, até mesmo as utilizações dos termos puta e trabalhadoras sexuais têm abertura para movimentações. Isto porque estas nomeações estão envoltas a constantes disputas; o termo trabalhadoras sexuais abrange a aposta no reconhecimento da prostituição como trabalho e a luta por direitos trabalhistas. Enquanto a palavra puta, assim como apostava Gabriela Leite (2013), representa a necessidade de torcer o sentido da palavra como meio de torná-la o anúncio da luta ao combate ao estigma que circunda a vida das prostitutas.

Por essas variações, escolhemos utilizar os termos puta, prostituta e trabalhadora sexual, como um modo de apontar a impossibilidade de capturar em apenas uma terminologia as multiplicidades que compõem as experiências na prostituição. Termos em disputa que neste texto são tomados por meio da confluência e aposta em compreender a prostituição como trabalho, assim como anunciar a positivação da puta na luta contra o estigma.

Retomando as apostas de Haraway (1995), diante da produção de saberes localizados é preciso a criação de uma rede de conexões que incluam a capacidade de traduzir conhecimentos entre diferentes comunidades. Pensando em uma forma de trazer as experiências das putas às discussões acadêmicas, e expor suas divergências assim como convergências sobre algumas perspectivas feminista a respeito da prostituição, optamos pelo modelo narrativo proposto pelo filósofo Walter Benjamin (1987).

A narratividade emerge como uma ferramenta metodológica que viabiliza denotar saberes e experiências que atravessam a zona e que são capazes de disputar outras versões sobre as histórias que normalmente se ouvem acerca das prostitutas. Assim, escolher especificamente as narrativas a partir da perspectiva de Benjamin (1987) se deu, 
uma vez que, nas proposições do autor, as narrativas surgem como um meio de questionar a posição neutra da história que nos é contada, e pôr em evidência outras narrativas.

As experiências narradas estão atreladas ao conceito de experiência proposto pelo autor, que as entendem como opostas à vivencia. Ou seja, as experiências de que tratamos são aquelas compartilhadas em comunidade (Benjamin, 1987). São aquelas que se repetem e que passaram entre a prostituta que inscreveu este trabalho e suas colegas.

Sobre estas últimas, seus nomes, ainda aqueles criados apenas para exercer o trabalho sexual, trocados por outros a fim de gerar maior discrição possível. Além disso, as aproximações entre a puta pesquisadora e suas colegas ocorriam quando colocando-a em posição de psicóloga e pesquisadora, as prostitutas resolviam desabafar e pedir que narrasse suas histórias. Através destes pedidos é que se configuraram as narrativas expostas neste trabalho.

As zonas pesquisadas são compostas por três cabarés diferentes, dois localizados no Estado do Espírito Santo e um no interior do Estado de São Paulo. Os puteiros em questão possuem modos e condições de trabalho distintos. Os três cabarés, ainda por ensejarmos discrição, são apelidados durante as narrativas a fim de localizarmos o leitor sobre onde as falas das prostitutas se localizam.

Citaremos o "cabaré inferninho", que é um puteiro localizado à beira de uma estrada no interior do Espirito Santo, onde as condições de trabalho não são tão boas, os valores dos programas variam entre 90 a 160 reais por hora, a higienização é falha e o lugar insalubre. Seu funcionamento ocorre de segunda a segunda a partir das $20 \mathrm{~h}$ até $2 \mathrm{~h}$. O local costuma ser frequentado por trabalhadores rurais da região e pequenos comerciantes, e nele circulam majoritariamente trabalhadoras sexuais pardas e negras.

O “cabaré chácara”, localizado no interior de São Paulo, é um lugar luxuoso e bem higienizado. Os programas ali possuem apenas um valor base que se inicia por 300 reais a hora, podendo aumentar de acordo com a decisão entre trabalhadoras e clientes. Ele possui dois turnos de funcionamento, e as trabalhadoras podem escolher em qual turno trabalhar: tarde ou noite. Funciona de segunda a sábado, e nele circulam mulheres que correspondem ao padrão estético vigente, majoritariamente brancas e loiras.

O "cabaré bar", localizado no interior do Espirito Santo, é próximo à praia, possui boa estrutura, porém menor que a do cabaré anterior. A higienização do local é mediana, às vezes descuidada, mas não se trata de um ambiente insalubre. Como o apelido sugere, sua estrutura assemelha-se a de um bar, o local é aberto e rodeado por uma piscina. Os valores dos programas variam entre 200 e 400 reais por hora, seu funcionamento ocorre 24 horas por dia e todos os dias da semana, as trabalhadoras podem escolher turnos de trabalho que durem pelo menos oito horas diárias, permitindo folga aos domingos. As mulheres que por ali circulam possuem tipos físicos variados, brancas, pardas e negras.

Nos três cabarés citados, as prostitutas não se fixam, viajam depois de alguns meses de trabalho. Ou viajam mais rapidamente, quando percebem que não têm bons ganhos. Finalizando estas considerações, é preciso alertá-los de que as narrativas e discussões a seguir estão escritas em primeira pessoa. Isto porque, além de apostarmos na posição corporificada da pesquisadora puta reverberando-se também em sua escrita, evidenciar o protagonismo das prostitutas que contribuíram na inscrição deste texto é uma aposta política. 


\section{Feminismo na zona? Será que eles chegam por lá?}

Trabalhando entre os diferentes cabarés pesquisados, percebi que as discussões sobre feminismo costumavam ser raras, e quando ocorriam eram em puteiros onde o nível de escolaridade entre as putas, por vezes, é maior quando comparado ao de outras colegas dos cabarés por onde passei. Certa vez, conversando despretensiosamente com uma colega chamada Nicole Helena, resolvi questionar se para ela o feminismo chegava na zona.

Nicole trabalhava no "cabaré inferninho", e me respondeu que o feminismo chega, chega para nos ensinar a nos valorizar como mulher; mas, como mulher puta, ela pensa que não. Disse ainda que às vezes se vê como objeto. E que é assim que o feminismo chega por ali: "me valorizo como mulher, mas não como trabalhadora. Sou uma espécie de objeto valorizado, e daí extraio o meu valor. Mas essa coisa de que temos que lutar por nossos direitos, acho que por aqui não passa”.

Com vistas às afirmações da colega Nicole, e a percepção de que eram raras as discussões sobre feminismos nos puteiros, penso sobre o que algumas teóricas feministas argumentam sobre o trabalho sexual e como isto chega na zona.

Inicio a discussão junto a Simone de Beauvoir (2016), e o que a princípio ressoa são suas palavras sobre a mulher e o feminino, e como elas apontam para a inexistência de uma essência imutável para estes termos. A autora argumenta que não busca enunciar verdades eternas e que após a maior parte de suas afirmações cabe subentender: "no estado atual da educação e dos costumes”. Portanto, levarei em consideração que as percepções de Beauvoir estão de acordo com a educação e os costumes da época em que viveu.

Notemos que já no ano de 1949, quando foi lançada a primeira edição da obra $O$ Segundo Sexo, pode-se ver considerações que entendem o casamento como análogo à prostituição. De acordo com Beauvoir (2016), semelhantes, o casamento e a prostituição aproximam-se quando pensamos o ato sexual como um serviço prestado por esposas e por prostitutas: para as primeiras, o ato sexual é um serviço, na medida que ele faz parte do cumprimento dos "deveres conjugais", o que não é uma graça, mas a execução de um contrato.

Nessa lógica, a esposa seria contratada para atender a um homem a vida inteira, enquanto a prostituta é contratada por vários que pagariam por vez. A diferença das duas relações estaria no preço e na duração do contrato. Beauvoir tece semelhanças e distinções nas posições da puta e da esposa. No movimento de evidenciar isso, ela sugere que

A grande diferença entre elas está em que a mulher legítima, oprimida enquanto mulher casada, é respeitada como pessoa humana, esse respeito começa a pôr seriamente em xeque a opressão. Ao passo que a prostituta não tem os direitos de uma pessoa; nela se resumem, ao mesmo tempo, todas as figuras da escravidão humana. (Beauvoir, 2016, p. 364)

Pensando a proposição da filósofa, e apesar de levar em consideração que suas ponderações se dão de acordo com os costumes e modos de pensar de sua época, pego-me confusa quanto ao seu posicionamento a respeito do assunto, mas, mais do que isso, questiono sobre o que a autora quis dizer ao afirmar "prostitutas" como aquelas em que se concentram, ao mesmo tempo, todas as figuras da escravidão humana? 
Ainda que Beauvoir (2016), logo após essas ponderações, continue sua escrita refutando teorias que compreendiam as prostitutas como criminosas degeneradas, bem como discordando dos moralistas de sua época, que debochavam das histórias comoventes das prostitutas, a autora segue um caminho contraditório, pois ao passo que entende a prostituição como trabalho, o sexo como um serviço, e ainda esboce afirmações como: "Em muitos casos, a prostituta teria podido ganhar a vida de outro modo, mas se o escolheu não lhe parece o pior" (Beauvoir, 2016, p. 365), e noutro ponto entende prostitutas como resumo de todas as figuras da escravidão humana.

Ora, se para a autora a prostituta pode escolher o modo de ganhar a vida, quem em sã consciência poderia optar por representar e resumir-se na figura da escravidão humana? Quando Beauvoir (2016) atrela a figura da prostituta à escravidão, compreendo que essas sugestões podem expressar a ideia de que uma prostituta é uma propriedade que pode ser transacionada, subordinada a um outro ser humano. Quando completamente subordinada, oprimida e miserável, a prostituição garantiria acesso ilimitado ao corpo da puta. A autora não faz estes apontamentos, mas algumas de suas ponderações acabam por abrir espaço para perspectivas que levam em consideração essas compreensões.

Como as perspectivas de Carole Pateman (1993, p. 299), que sugere "que na prostituição o corpo da mulher e o acesso sexual ao seu corpo são objetos de contrato", e que, portanto, ter corpos à venda no mercado, enquanto corpos, é muito parecido com a escravidão. Seguirei expondo algumas concepções desta autora sobre prostituição, de modo a demonstrar como essas proposições se entremeiam à fala de Nicole sobre como o feminismo chega na zona.

Se por um lado Pateman (1993), em sua obra Contrato sexual, afirma que o contrato de casamento é um dos caminhos sociais aceitáveis para os homens terem acesso sexual ao corpo das mulheres, e ainda assim a sujeição sexual das esposas não deixou de ser defendida. Noutro ponto, em oposição, temos a prostituição - que até recentemente era difícil encontrar alguém que a defendesse.

Citando as reflexões de Beauvoir (2016) sobre a esposa ser contratada por um homem só, e a prostituta por vários, Pateman (1993) ainda sugere que as prostitutas como mulheres comercializam seu corpo, mas, diferentemente das esposas, recebem por isso. Ela ainda afirma que prostitutas estão submetidas aos clientes, assim como esposas estão submetidas aos maridos. Seus argumentos se voltam, então, criticamente àqueles que ela entende como defensores da prostituição.

Para a autora, a prostituição é a utilização do corpo da mulher por um homem para sua própria satisfação. Não há desejo ou satisfação por parte da prostituta, uma vez que a prostituição não é uma troca prazerosa e recíproca na utilização dos corpos, mas a utilização unilateral do corpo de uma mulher por um homem em troca de dinheiro (Pateman, 1993).

Apesar de citar que, desde os anos 1970, prostitutas têm se organizado nos Estados Unidos, na Grã-Bretanha e na Austrália, a fim de melhorar suas condições de trabalho, combater a violência e requererem o reconhecimento como trabalhadoras, a teórica segue afirmando que os "defensores da prostituição" atribuem a não compreensão da prostituta como trabalhadora às posturas distorcidas em torno das relações sexuais e à hipocrisia. Por mais que ela concorde que há hipocrisia, apenas esta última não seria capaz de apreender as emoções com as quais alguns homens encaram as prostitutas (Pateman, 1993). 
Para a autora, mais que por causa da hipocrisia, prostitutas são assassinadas por clientes, pois são encaradas como fonte de sujeira, e, ao contrário dos outros trabalhadores, correm riscos todos os dias de sofrer danos físicos por parte dos clientes, mas não por inadequação ou ausência de regras de segurança, mas apenas porque são mulheres (Pateman, 1993).

Pensando sobre estas posições, a "Casada”, uma colega puta que leva este apelido por ser comprometida, senta-se no sofá vermelho daquele "cabaré bar", acende um cigarro de palha e balança os pés como quem demonstra ansiedade. Como de costume, argumentando de maneira incisiva e às vezes risonha, questiona se é, portanto, duas vezes escrava, escrava de todos e de um só, desde o momento de esposa até o momento de prostituta.

Ela sorri e afirma que, frente a tantos senhores, não pertence a nenhum. A Casada nos incita a pensar que estes lugares pressupostos de passividade não nos cabem. Passeando de um lado a outro do cabaré, agora nos excita, e grita: "todos que transam por aqui e comigo não me defendem, nem ao menos simbolicamente, e no sentido lato, me fodem. Quanto ao esposo, permaneço em defensiva, não defendida".

A narrativa da Casada mostra outro ponto que não foi levado em consideração, quando Beauvoir (2016) entende que a mulher casada é respeitada como pessoa humana, enquanto a prostituta não tem esse respeito. Assim como quando Pateman (1993) afirma que prostitutas estão em risco porque são atreladas à sujeira, isto é, à imoralidade, e por serem mulheres. Parece-me que, apesar do correlato entre as posições de esposa e prostitutas ser imprescindível no sentido de compreender as assimetrias que compõem alguns lugares ocupados pela mulher heterossexual na sociedade, é necessário que lembremos que o respeito enquanto pessoa que corre na pele da mulher casada é falho.

Quando pensamos a respeito dos casos de feminicídio e outros tipos de violência contra a mulher que ocorrem majoritariamente dentro das relações amorosas e conjugais, entendemos que a respeitabilidade concernida ao posto de "mulher honesta" é frágil e violável, e não cabe inteiramente como defesa contra violência.

Apesar da correlação entre matrimônio e prostituição, essa dualidade entre esposa e prostituta mancha a compreensão de que as mesmas podem ocupar as duas posições. Contra as prostitutas, alguns creem que se podem justificar atos de violência, desrespeito e exclusão devido à sua transgressão. Paradoxalmente ou obviamente, ao tratar-se daquelas que ocupam o outro lado do ponto, o dito lugar da "mulher honesta", os mesmos atos justificam-se por questões moralmente menos condenáveis para eles, como o uso de roupas mais justas, ou um adultério, por exemplo. Notem, então, que se trata apenas de opostos inventados.

Desses opostos inventados pode-se notar a fala de Nicole que afirma como o feminismo chega ao puteiro: a colega disse que se valoriza como mulher, mas não como prostituta, e que se vê como objeto. Como se para se valorizar como mulher fosse necessário deixar de ser puta. Os feminismos nos puteiros pesquisados quase não chegam, e quando chegam vêm com percepções muito parecidas com as de Pateman (1993). Os feminismos chegam soando como: ou se trabalha na putaria, ou se valorize como mulher. 


\section{Fodendo a hipocrisia: sexo é trabalho e putas são profissionais}

Sobre o que falaremos agora? Mari, com ares de chateação, chega àquele puteiro localizado a beira da pista, vulgo inferninho. Olha-se de frente ao espelho, se irrita e corta nossas discussões, interrompe toda a teorização. Transformadora de fagulha em fogaréu, no momento de discórdia ela é quem teoriza.

Mari, pessoa que atravessa nosso diálogo de maneira saltitante e nervosa, fez os teus olhos correrem até este ponto, para poder gritar: "Quem comeu meu doce, quem além de puta é ladra?". "O além de", colocação que costuma iniciar uma frase onde a palavra puta e tudo que se relaciona a ela é pejorativo, é comum até no puteiro. Com outro doce na boca, nossa colega afirma que prostituição não é trabalho e que ser puta é feio, sim, e que a maioria aqui no "cabaré inferninho" tem vergonha.

Ela afirma que o dinheiro da faxineira, da empregada doméstica, do garçom, da manicure e qualquer outro conquistado através de trabalhos precarizados é mais honroso que o dela. Todas nós de olhos arregalados, Mari diz que isto que acabara de ouvir em nossa conversa sobre comparações entre mulheres vistas como boa moça e putas é balela. Em postura desafiadora, diz que aprendeu isto desde criança, seus amigos, familiares, alguns outros religiosos conhecidos e até outras colegas de trabalho têm a mesma opinião. Ela oferece o doce a todos, diz que um cliente que lhe deu. Retira-se da cena, afirma que vai atender o cliente, e que a gente perde tempo com toda essa conversa fiada.

Na discussão anterior, junto a Beauvoir, vimos sua compreensão sobre o sexo como um serviço, no entanto, não me aprofundei na questão. Além disso, não fiz críticas às perspectivas de Pateman sobre a prostituição, das quais discordo, pois optei por mostrar que aquelas percepções chegam ao puteiro sem muitas alterações. Todavia, ao levar em consideração as percepções de Mari sobre a prostituição não ser um trabalho, neste momento opto por pensarmos mais especificamente sobre o assunto. Para isso, evoco as perspectivas de outras teóricas feministas e as entrecruzando à questão.

Silvia Federici (2012), assim como Beauvoir, entende que o sexo é um trabalho para a mulher, uma vez que compreende que um dos deveres sexuais da mulher numa relação heterossexual é proporcionar prazer ao homem. Para a autora, o sexo é trabalho na medida em que o dever de agradar está tão embutido na sexualidade feminina que chegamos a aprender a ter prazer em dar prazer, e aí reside sua consideração a respeito de nossa submissão sexual.

Ainda pensando sobre o quão trabalhoso pode ser se relacionar sexualmente com um homem, a autora sugere que não nos é permitido esquecer a troca envolvida, porque não costumamos transcender a relação de valor em nossa relação de amor com um homem. A maioria dos encontros sexuais para mulheres são, então, gastos em cálculos. Suspiramos, soluçamos, ofegamos, pulamos e mergulhamos na cama, mas, enquanto isso, nossa mente continua calculando "quanto, quanto mais podemos nos entregar?" (Federici, 2012, não paginado), isto é:

Se é o nosso primeiro encontro, é quanto podemos permitir que ele consiga: ele pode ir até a nossa saia, abrir a nossa blusa, colocar os dedos sob o nosso sutiã? Em que ponto devemos dizer a ele para parar, com que intensidade devemos nos recusar? (Federici, 2012, não paginado) 
Observando o que sugere Federici (2012), imaginem se todas as mulheres passassem a cobrar diretamente aos homens por esses serviços. Nos puteiros, a pergunta “Quanto mais?” é utilizada por prostitutas. Nós também calculamos quanto tempo falta para acabar o programa, e sobre "quanto mais" precisamos para conseguir "aquela grana para quitar determinada conta?", "quanto mais posso e quero oferecer àquela transa?".

Mas não é só por nós que esta pergunta é feita. Ao contrário do que disse Pateman (1993) sobre a ideia de na prostituição haver corpos à venda, no momento em que disponibilizamos nossos serviços sexuais, e não nossos corpos, como afirma a autora, a pergunta "quanto mais" é realizada também pelos clientes. Eles não perguntam "quanto mais deste corpo posso comprar, e levar para casa?”, o que corresponderia caricatamente às afirmações da autora.

Normalmente pergunta-se "quanto mais preciso pagar para aumentarmos o tempo do programa?”. De maneira menos formal, questionam também sobre o que fazemos na cama, algo como "faz anal, boquete, com ou sem camisinha?", o que pode ser entendido como até onde eles poderão ir no ato sexual. "O que mais fazemos", "quanto mais" são perguntas realizadas, portanto, tanto por clientes quanto por trabalhadoras sexuais.

Tomando em consideração essas questões, a fim de reafirmar o trabalho sexual como um trabalho, os levarei a outro ponto. Revirando um tanto repentinamente o foco dessa discussão, ainda junto a Federici (2017), pensaremos os entrelaçamentos históricos entre o trabalho feminino e sua desvalorização, e como a prostituição feminina heterossexual se relaciona com isso.

Inicio realizando incursões na história sobre a desvalorização do trabalho feminino que, de acordo com Federici (2017), está vinculada à criminalização e ao controle do Estado sobre a procriação. Segundo a autora, a criminalização do aborto gerou consequências importantes na organização capitalista do trabalho. A maternidade que a partir disso fora submetida à condição de trabalho forçado, confinou as mulheres à atividade reprodutiva de uma maneira que ainda não se havia visto em sociedades ocidentais anteriores.

Nessa mesma época, em torno do século XV até o XVII na Europa, mulheres haviam perdido espaço no mercado de trabalho. Isto se dava junto à imposição de que mulheres não deveriam trabalhar fora de casa. Impunha-se que se centrassem em suas atividades reprodutivas e domésticas. As proletárias, em particular, encontravam dificuldades para obter qualquer emprego além daqueles de baixo status, como os de empregadas domésticas e trabalhadoras rurais, por exemplo (Federici, 2017).

Junto à condição da maternidade como trabalho forçado atrelada à diminuição do espaço no mercado trabalho, os trabalhos domésticos realizados por mulheres passaram a ser vistos como sem nenhum valor, ainda que voltados ao mercado (Federici, 2017). De modo geral, o trabalho doméstico, como ainda é visto atualmente, já não era entendido como um trabalho.

Nesse movimento, Federici (2017) ainda afirma que os valores arrecadados por mulheres não eram suficientes para sua sobrevivência, e, em meio a tudo isso, o casamento emergiu como uma verdadeira carreira, uma vez que a incapacidade de elas sobreviverem sozinhas era dada como certo. Neste cenário, já no século XVI, devido a perda de poder em relação ao trabalho assalariado e a expropriação das mulheres camponesas das suas terras, ocorre a massificação da prostituição. 
Faço este sucinto passeio por algumas condições históricas sobre o trabalho feminino, tendo em vista que, embora o trabalho assalariado, o doméstico e o sexual costumem ser estudados separadamente, ao entrelaçá-los pode-se notar como a discriminação sofrida por mulheres como mão de obra remunerada está atrelada à proibição e desqualificação da prostituição como trabalho.

Se, assim como afirma Federici (2017), a discriminação das mulheres como mão de obra remunerada está diretamente relacionada à sua função como trabalhadoras não assalariadas do lar, a aparição da figura da dona de casa, e a redefinição da família como lugar imposto à força de trabalho feminina, acabaram por fazer com que tanto o trabalho sexual como o doméstico não fossem compreendidos como trabalho.

Nesse sentido, comercializar o trabalho sexual por si só já era algo transgressivo e proibido, apesar de as mulheres precisarem dele para sobreviver. Como podem perceber, mesmo frente a séculos de diferenças, comercializar o serviço sexual ainda aparece como algo transgressor. Inclusive, no final do século XV, aquelas que ousavam trabalhar fora de casa, em um espaço público, eram representadas como megeras sexualmente agressivas, putas ou bruxas.

Se a prostituição até a Idade Média havia sido aceita como mal necessário, e prostitutas haviam se beneficiado de um alto regime de salários, quando a prostituição se tornou viável para a sobrevivência feminina frente ao cenário de imposição às mulheres como não assalariadas do lar, passou-se então a criminalizá-la (Federici, 2017).

Por isso, observem que empobrecer os corpos femininos, fazê-los dependentes, e punir aqueles que ousam fazer arranjos para mudar esta condição, era e ainda é um meio de controle da sexualidade feminina. A criminalização imputada já naquela época castigou as prostitutas, e assim, as mulheres que transgrediam as regras impostas corriam o risco da destruição moral e física, uma vez que, segundo Federici (2017), apenas a declaração de um homem afirmando que uma mulher era uma prostituta ou que cedeu aos seus impulsos sexuais poderia gerar castigos que iam desde a morte até a exclusão social.

As prostitutas, especialmente aquelas que trabalhavam na rua, eram severamente penalizadas: banimento, flagelação e outras formas cruéis de reprimendas. Entre elas, a cadeira de imersão... em que as vítimas eram atadas, às vezes presas numa jaula, e, então repetidamente imersas em rios ou lagoas até quase se afogarem. ... Enquanto isso, na França do século XVI, o estupro de prostitutas deixou de ser crime. ... Se fossem pegas em flagrante deveriam receber cem chibatadas e, depois, serem banidas da cidade por seis anos. (Federici, 2017, p. 187)

Andamos em passos lentos em meio à hipocrisia passada e atual para perceber que "Isso que chamam de amor, nós chamamos de trabalho não remunerado" (Federici, 2015, [tradução nossa]). Mudando um pouco os ares, saindo da exposição de castigos, e saltando entre séculos, ao fazer comparações entre o trabalho sexual remunerado e o combo dos trabalhos domésticos realizados dentro do seio familiar, assim como Federici (2015), entendo que há uma confusão entre amor e serviço pessoal, uma vez que os serviços domésticos e reprodutivos assim como sexuais são, por vezes, colocados como modo de demonstração afetiva e, portanto, não como um trabalho. 
Essas confusões podem ser vistas também no puteiro, em contato com clientes. Certa vez, naquele puteiro rico que mais parece uma chácara, ainda na cama com o cliente, ele me disse que gostaria que eu fosse sua namorada, que ele se sente especial ao meu lado, e a única coisa chata é ter que pagar. Costuma dizer que me ama, e diz que gostaria que fosse recíproco, pois, se fosse, ele não precisaria me pagar.

Isto, que não passa apenas por mim, pode ser visto em narrativas como a de "Jorginho por amor”. Lenda naquele cabaré situado perto da praia, Jorginho é um nome famoso por lá. As putas costumam desanimar quando sabem que é Jorginho que está no salão a espera de companhia. Ainda assim, continuam em pé de frente para ele, afinal, não se pode fazer desfeita a um cliente, são normas do trabalho. Jorginho aproxima-se de Mari e relata que o seu cheiro é tão doce que o faz suspirar.

Ele se considera um galanteador à moda antiga, e não há puta que discorde. Mari é a escolhida. Combinam de fazer o pagamento lá na hora, Jorge ainda não decidiu quanto tempo gostaria de passar com a garota, e por ser cliente antigo, permitem que a puta vá com ele. Os dois chegam ao motel, Mari logo resolve despir-se e tasca um beijo no cliente, ele não gosta, pede que ela vá devagar, com carinho.

Ela concorda, beijo na nuca, na boca, vai pelo peito, barriga, até... opa, Jorginho gozou. Ele fala que foi ótimo, mas que já não tem mais idade para essas coisas, e que precisa ir embora. Mari agradece e cobra o valor do programa, Jorginho salta da cama dizendo que foi tudo por amor, e que quando existe amor não há dinheiro que pague. Mari se revolta, diz que a transa dela é paga e ponto. Grita, esperneia, ameaça ligar para o patrão; Jorginho diz que vai pagar, diz que desencantou, pois ela grita muito. "Deixei de te amar, agora já posso pagar", afirma Jorginho.

Esta última frase dita pelo "Jorginho por amor" me faz pensar que, não à toa, Federici (2015) sugere que, por vezes, uma mulher que reluta em fazer o trabalho doméstico é vista como má ou como quem não se importa com a relação. Assim como aquela que não está disponível sexualmente o tempo inteiro para o marido é entendida como quem não se preocupa em manter o matrimônio.

Quando esta confusão entre serviços pessoais e amor passa pelo puteiro, vê-se que clientes tentam seduzir prostitutas, afirmando que sentem algo por elas ou que gostariam de encontrá-las em outro momento, sem essa cobrança por tempo de programa e por pagamento.

Para compreendermos um pouco mais estas confusões entre amor e serviço pessoal, a socióloga Viviane Zelizer (2011) nos ajuda, uma vez que, ao discutir as negociações da intimidade, ela sugere que relações de intimidade sexual com frequência incluem transferências monetárias. E os envolvidos, porém, têm o cuidado de estabelecer se o relacionamento é casamento, namoro, prostituição ou algum tipo de laço social.

Zelizer (2011) ainda questiona por que as pessoas se preocupam tanto em achar o tipo correto de pagamento para as suas várias relações íntimas. E afirma que para alguns críticos sociais, amor e sexo permanecem no campo das permutas bloqueadas, isto é, não se deveria cobrar por sexo. Isto porque esta troca pode confundir a diferenciação entre o sistema sexual e o econômico. 
O receio emerge junto à percepção de que quando os relacionamentos ganham uma natureza comercial, reside no questionamento sobre o que restaria para os relacionamentos que não "possuem” natureza comercial. Isto é, quando a vida de alguém torna-se pouco mais que uma série contínua de transações comerciais, o que acontece com os tipos de relacionamentos recíprocos tradicionais que nascem do afeto, amor e dedicação? (Zelizer, 2011).

A autora argumenta que a preocupação com a sacralidade das coisas e o risco de tudo pôr-se à venda são causas da mistura entre intimidade e transações econômicas serem vistas, por alguns, como uma anomalia perigosa que requer medidas de proteção. Não sem motivos, há uma tentativa social em proibir que vendamos nosso sexo, mas que não vê problemas quando vendemos nosso tempo, pensamento e comportamento (Zelizer, 2011).

Além dessas questões, Zelizer (2011) alerta que há uma falha usual sobre estas perspectivas, uma vez que não reconhecem como transações monetárias as relações em que, por exemplo, pais pagam babás para que cuidem de seus filhos, casais divorciados em que um paga e outro recebe a pensão, ou as mesadas que alguns pais dão para os filhos.

Estas falhas em reconhecer como muitas relações de intimidade estão cercadas por transações financeiras, me fazem relembrar a afirmação de Beauvoir (2016) sobre o fato de que do ponto de vista econômico, a diferença entre a esposa e a puta está no preço e na duração do contrato. A grande questão perpassa aquilo que Monique Prada (2018, p. 72) já bem sugeriu: "ao colocar preço no trabalho sexual que executa, a prostituta pode, de algum modo, subverter a lógica de que os trabalhos domésticos e sexuais devem ser oferecidos sem que se pague nada por eles".

Entretanto, lembremos que isto não faz da prostituição uma atividade feminista ou revolucionária em si; aliás, no puteiro, a sexualidade é posta a serviço do cliente que, normalmente, é um homem conservador e machista (Prada, 2018). Basta que lembremos das presepadas do "Jorginho por amor".

\section{Considerações finais}

Caminhar entre os diferentes cabarés e anunciar aquilo se repetia em ambos, foi uma aposta para pensar sobre os feminismos por ali. Mas se a priori minha expectativa enquanto puta, feminista e pesquisadora era aquela apontada por Prada (2018, p. 38) sobre "o feminismo ter chegado no puteiro, sim, e não ter sido graças às feministas conservadoras”, em minhas caminhadas, dei-me de frente a outra constatação.

As discussões sobre feminismos eram majoritariamente suscitadas por mim, e os debates acalorados sobre o assunto pareciam ligar-se àquelas ponderações que não compreendem a prostituição como trabalho e que passeiam ao longe da luta contra o estigma da puta. Além disso, em boa parte do tempo, o silêncio sobre o assunto assim como o jeito como as putas ignoravam as machistas ponderações de alguns clientes, me faziam crer ingenuamente que os feminismos não deveriam mesmo chegar por lá. Caso contrário, a putaria veria seu fim.

A putaria veria seu fim na medida em que tanto as concepções salvacionistas como aquelas que romantizam o trabalho sexual não cabem naquelas realidades. Ainda assim, os estudos construídos "sobre” nós e não "conosco", quando excepcionalmente chegam a atravessar as portas dos cabarés, o fazem como áureas culpabilizantes que ressoam nas falas das putas que conheci. 
Entre um questionamento e outro, compreendi que se alguns discursos feministas não conseguem abranger as experiências dessas mulheres, não há por que elas os ouvirem ou os usarem. O que se pode apreender dessas andanças por cabarés é que as prostitutas não só não estão aí para serem salvas como belas vítimas indefesas, como também são capazes de ignorar o que não lhes serve.

\section{Nota}

1 Nome mais conhecido no movimento de defesa dos direitos das prostitutas no Brasil, Gabriela faleceu em 2013, aos 62 anos. 


\section{Referências}

Beauvoir, Simone (2016). O segundo sexo. Nova Fronteira.

Benjamin, Walter (1987). Obras escolhidas 1: magia e técnica, arte e política: ensaios sobre a literatura e história da cultura (Sérgio P. Rouanet, trad., $3^{\mathrm{a}}$ ed.). Brasiliense.

Diniz, André G. R. \& Mayorga, Cláudia (2018). Notas sobre autonomia e desqualificação social de mulheres prostitutas. Psicologia E゚ Sociedade, 30. Recuperado de https://doi. org/10.1590/1807-0310/2018v30165432

Douville, Olivier (2007). A jovem prostituta e sua mãe. Tempo Psicanalítico, 39, 51-6.

Federici, Silvia (2012). On Sexuality as Work. The Commoner, 15, 88-94. (Original publicado em 1975).

Federici, Silvia (2015, 21 de abril). El Patriarcado del Salario: "Lo que llaman amor, nosotras lo llamamos trabajo no pagado". Comunitariapress. Recuperado de https://comunitariapress. wordpress.com/2015/04/21/el-patriarcado-del-salario-lo-que-llaman-amor-nosotras-lo-llamamos-trabajo-no-pagado/

Federici, Silvia (2017). Calibã e a bruxa. Elefante.

Haraway, Donna (1995). Saberes Localizados: a questão da ciência para o feminismo e o privilégio da perspectiva parcial. Cadernos Pagu, 5, 7-41. Recuperado de https://periodicos.sbu. unicamp.br/ojs/index.php/cadpagu/article/view/1773.

Leite, Gabriela (2013). Por que Gabriela gosta da palavra puta / Why Gabriela prefers the word puta (wore). Um Beijo para Gabriela. Recuperado de https://www.youtube.com/ watch? $\mathrm{v}=\mathrm{CvKkGPiXvOo}$

Lopes, Cocimar S., Rabelo, Ionara V. M., \& Pimenta, Rosely P. B. (2007). A Bela Adormecida: estudo com profissionais do sexo que atendem à classe média alta e alta na cidade de Goiânia. Psicol. Soc., 19(1), 69-76. Recuperado de http://www.scielo.br/scielo.php?script=sci artt ext\&pid $=$ So $10271822007000100010 \&$ lang $=$ pt

Marchiori, Hilda (1983). Personalidad de la mujer delincuente. In Piña, Javier (Coord.), La mujer delincuente (pp. 191-205). Universidad Nacional Autônoma de México.

Molina, Anna M. R. (2003). Prostituição juvenil: uma condição existencial em busca de seus sentidos. Psicologia: ciência e profissão, 23(2), 22-29. Recuperado de http:// pepsic.bvsalud.org/ scielo.php? script $=$ sci arttext\&pid $=$ S 1414-98932003000200005\&lng $=p t \& t \operatorname{lng}=p t$

Pateman, Carole (1993). O contrato sexual. Paz e Terra.

Piscitelli, Adriana (2005). Apresentação gêneronomercado do sexo. Cad.Pagu,25, 7-23. Recuperado de http://www.scielo.br/scielo.php? script=sci arttext\&pid=S0 10483332005000200001.

Piscitelli, Adriana (2012). Feminismos e Prostituição no Brasil: Uma leitura a partir da Antropologia Feminista. Cuadernos de Antropología Social, 36, 11-31.

Prada, Monique (2018). Putafeminista. Veneta.

Zelizer, Viviana (2011). A negociação da intimidade. Vozes. 


\section{ADRIELY CLARINDO \\ https://orcid.org/0000-0003-3977-1163}

Psicóloga, mestre em Psicologia Institucional da Universidade Federal do Espírito Santo (UFES). Doutoranda em Antropologia Social na Universidade Estadual de Campinas (UNICAMP). Prostituta e feminista.

Endereço: Rua Cora Coralina, 100, Campinas/SP, CEP 13083-896.

E-mail: drica-clarindo@hotmail.com

\section{JÉSIO ZAMBONI \\ https://orcid.org/0000-0002-0360-7284}

Professor adjunto do Departamento de Psicologia e professor permanente de pós-graduação em Psicologia Institucional da Universidade Federal do Espirito Santo, Vitória, ES.

E-mail: zambonijesio@gmail.com

\section{RAFAELA WERNECK ARENARI MARTINS \\ https://orcid.org/0000-0003-1164-7021}

Mestranda no Programa de Psicologia Institucional da Universidade Federal do Espírito Santo, graduada em Psicologia pela Universidade Federal Fluminense.

E-mail: rafaelaarenari@gmail.com

\begin{tabular}{|c|c|}
\hline Histórico & $\begin{array}{l}\text { Submissão: 08/03/2020 } \\
\text { Revisão: 12/09/2020 } \\
\text { Aceite: 20/09/2020 }\end{array}$ \\
\hline $\begin{array}{l}\text { Contribuição } \\
\text { dos autores }\end{array}$ & $\begin{array}{l}\text { Concepção: A.C., J.S. } \\
\text { Coleta de dados: A.C. } \\
\text { Análise de dados: A.C.; J.S.; R.M. } \\
\text { Elaboração do manuscrito: A.C.; J.S.; R.M. } \\
\text { Revisões críticas de conteúdo intelectual importante: } \\
\text { A.C.; J.S. } \\
\text { Aprovação final do manuscrito: A.C. }\end{array}$ \\
\hline Financiamento & $\begin{array}{l}\text { Coordenação de Aperfeiçoamento de Pessoal de Nível Superior - Brasil } \\
\text { (CAPES) - Código de Financiamento } 001\end{array}$ \\
\hline
\end{tabular}

